\title{
An Investigation of the Erosion Wear of Pitched Blade Impellers in a Solid-Liquid Suspension
}

\author{
T. Jirout, I. Fořt
}

This paper reports on a study of the erosion wear mechanism of the blades of pitched blade impellers in a solid-liquid suspension in order to determine the effect of the impeller speed $n$ as well as the concentration and size of the solid particles on its wear rate. A four-blade pitched blade impeller (pitch angle $\alpha=30^{\circ}$ ), pumping downwards, was investigated in a pilot plant fully baffled agitated vessel with a water suspension of corundum. The results of experiments show that the erosion wear rate of the impeller blades is proportional to $n^{2.7}$ and that the rate exhibits a monotonous dependence (increase) with increasing size of the particles. However, the erosion rate of the pitched blade impeller reaches a maximum at a certain concentration, and above this value it decreases as the proportion of solid particles increases. All results of the investigation are valid under a turbulent flow regime of the agitated batch.

Keywords: pitched blade impeller, erosion wear, solid-liquid suspension.

\section{Introduction}

In all areas of particulate technology where solid particles are handled, structures coming into contact with particles exhibit wear. A major constraint of high intensity agitation is the possibility of developing erosion wear of the impeller blades due to the presence of solid particles in the liquid. $[5,6]$ In some applications, this wear can be so severe as to limit the life of a component, while in others it may be negligible [2]. All particles cause some wear, but in general the harder they are, the more severe the wear will be [3]. The materials used in plants differ in their susceptibility to erosive wear in the mechanism by which such wear occurs.

The erosion of a pitched blade impeller caused by particles of higher hardness (e.g. corundum or sand) can be described by an analytical approximation in exponential form of the profile of the leading edge of the worn blade (Fig. 1)

$$
H(R)=1-C \exp [k(1-R)],
$$

where the dimensionless transversal coordinate along the width of the blade is

$$
H=\frac{y(r)}{h}
$$

and the dimensionless longitudinal (radial) coordinate along the radius of the blade $r$ is

$$
R=\frac{2 r}{D} \text {. }
$$

Parameters $h$ and $D$ characterize the blade width and the diameter of the impeller, respectively.

The values of the parameters of Eq. (1) - the wear rate constant $k$ and the geometric parameter of the worn blade $C$ were calculated by the least squares method from the experimentally formed profile of the worn blade. While the wear rate constant exhibits a monotonous dependence both on the hardness of the solid particles and on the pitch angle $\alpha,[1,2]$ the geometric parameter of the worn blade is dependent on the pitch angle and, in linear form, on time. A recent investigation [2] shows that the latter parameter decreases hyperbolically with increasing blade hardness. All mentioned investigations were carried out in the same scale of the pilot plant mixing equipment (diameter of the vessel $D=300 \mathrm{~mm}$ ).

This study attempts to extend our knowledge about the influence of the parameters of the mixing process, and also the influence of the characteristics of the solid-liquid suspension on the erosion wear of the blade of pitched blade impellers, i.e. to determine the effect of the concentration and size of the solid particles on both parameters of Eq. (1), and finally to observe the effect of impeller speed $n$.

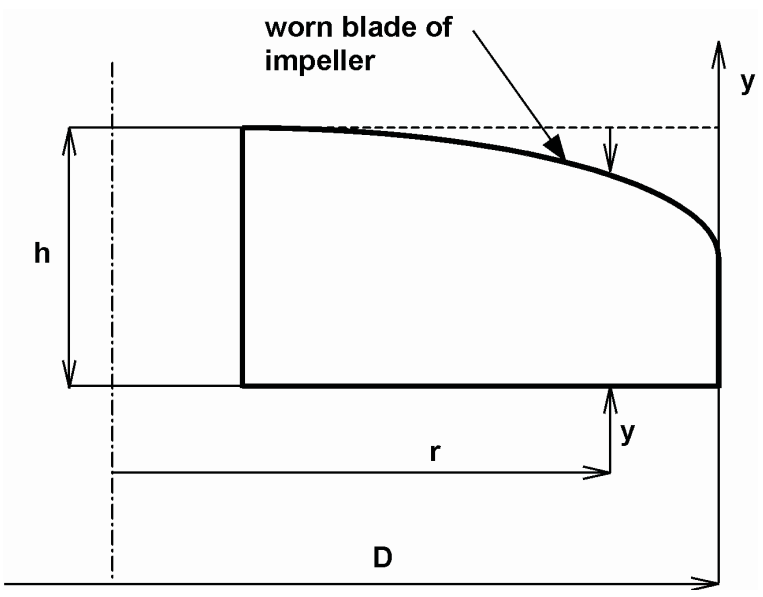

Fig. 1: Radial profile of the leading edge of the worn blade of a pitched blade impeller

\section{Experimental Setup}

A pilot plant mixing vessel made from stainless steel was used (Fig. 2), with water as a working liquid (density $\rho_{l}=1000 \mathrm{~kg} / \mathrm{m}^{3}$, dynamic viscosity $\mu=1 \mathrm{mPa} \cdot \mathrm{s}$ ) and particles of corundum (see Table 1).

Pitched blade impellers with four adjustable inclined plane blades made from construction steel (pitch angle $\alpha=30^{\circ}$ ), pumping downwards were investigated in a fully baffled flat bottomed cylindrical agitated vessel (vessel diameter $T=300 \mathrm{~mm}$, four baffles of width $b=30 \mathrm{~mm}$, impeller 


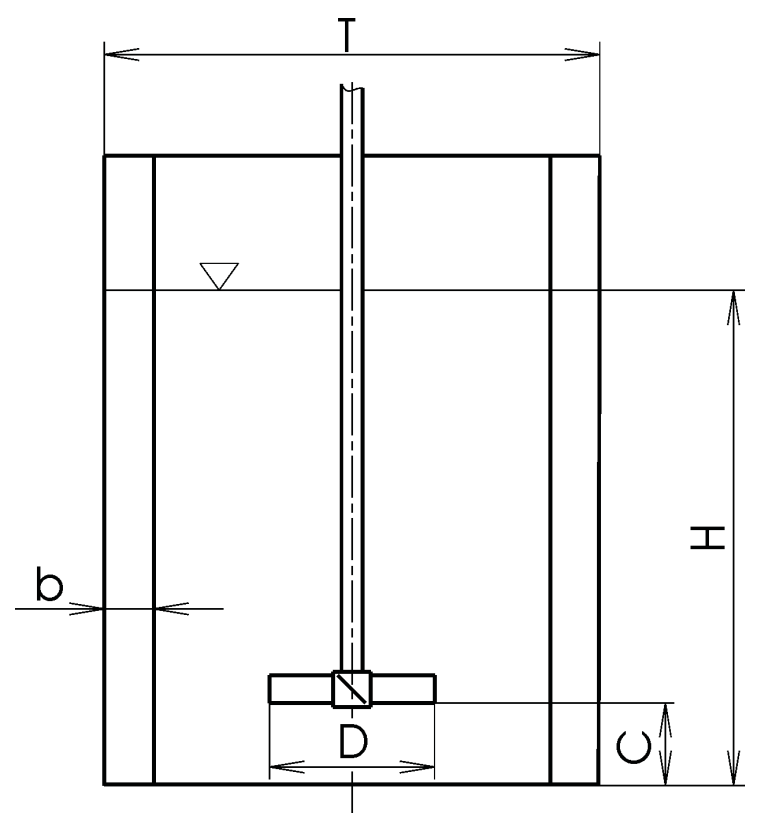

Fig. 2: Geometry of the pilot plant mixing vessel $T=300 \mathrm{~mm}$, $H / T=1, D / T=1 / 3, C / D=1, b / T=1 / 10 \mathrm{~b} / \mathrm{T}=1 / 10$

diameter $D=100 \mathrm{~mm}$, impeller off-bottom clearance $C=100 \mathrm{~mm}$ ).

The impeller speed was held constant $n=900 \mathrm{~min}^{-1}$ during an investigation of the influence of the suspension characteristics (see Table 1), and three levels of this quantity $\left(900 \mathrm{~min}^{-1}, 1050 \mathrm{~min}^{-1}\right.$ and $1200 \mathrm{~min}^{-1}$ ) were selected for determining the dependence of the wear rate on the impeller speed (for average particle size $d_{p}=0.29 \mathrm{~mm}$ and volumetric particle concentration $c_{V}=5 \%$ ). The impeller speed was held within accuracy $\pm 1 \%$ and the lowest level of this quantity corresponded for all investigated values of $d_{p}$ and $c_{V}$ to complete homogeneity of the suspension under a turbulent regime of flow of an agitated batch. The preliminary experiments were made visually in a perspex mixing vessel under the same conditions as for the erosion wear experiments. It follows from the results that, for all considered sizes and concentrations of the particles of corundum, there was $90 \%$ homogeneity of the suspension at impeller speed $n=700 \mathrm{~min}^{-1}$.

\section{Experiments}

During the experiments, the shape of the blade profile was determined from magnified copies of the worn impeller blades scanned to a PC (magnification ratio 2:1). The parameters of the blade profile for the given time of the erosion process were determined from each curve of four individual worn impeller blades. The selected time interval from the very beginning of the each experiment was not to exceed the moment where the impeller diameter began to shorten. Then the values of the parameters of Eq. (1) - the wear rate constant $k$ and the geometric parameter of the worn blade $C-$ were calculated by the least squares method from the experi-
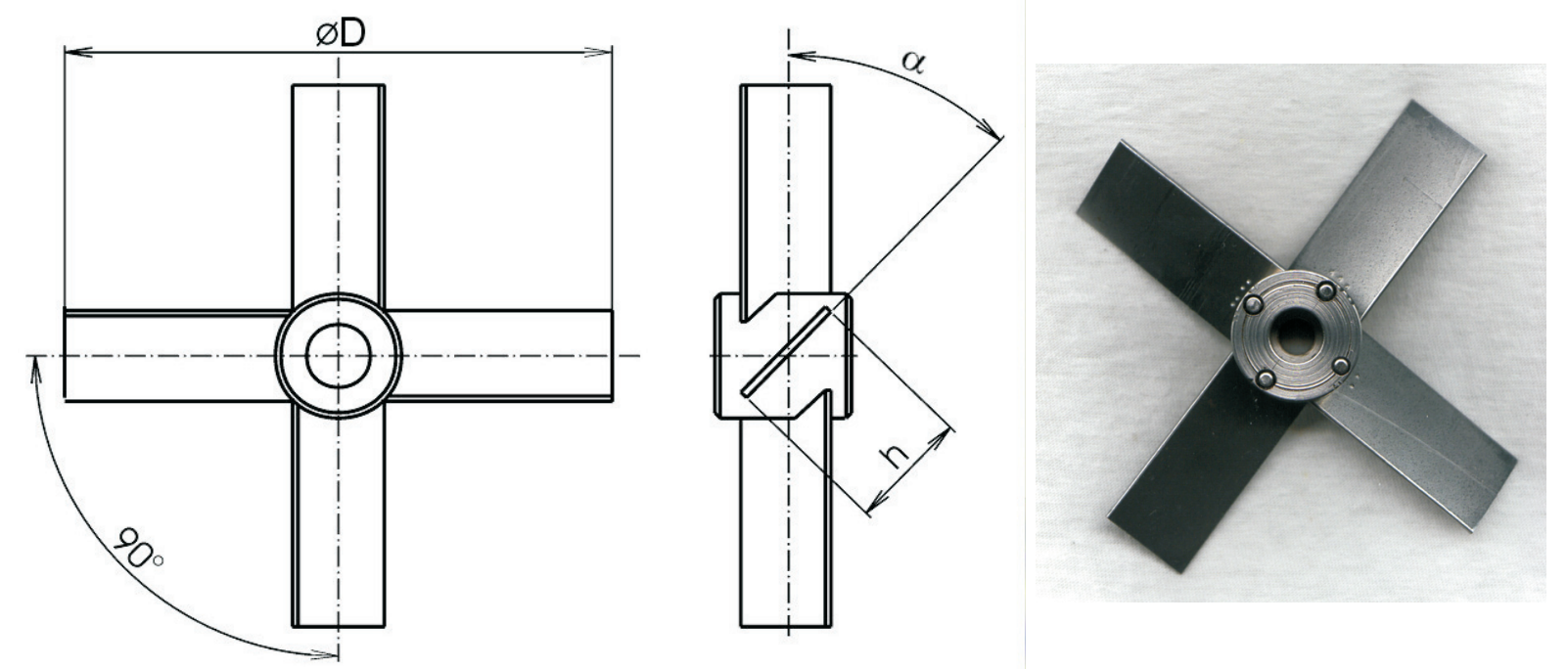

Fig. 3: Design of a pitched blade impeller with four inclined plane blades $D=100 \mathrm{~mm}, D_{0}=20 \mathrm{~mm}, h=20 \mathrm{~mm}, s=1.00 \pm 0.05 \mathrm{~mm}$, $\alpha=30^{\circ}$

Table 1: Survey of the water-corundum suspensions used in the experiments

\begin{tabular}{|c|c|c|c|}
\hline $\begin{array}{c}\text { Indication } \\
\text { of particle grain }\end{array}$ & $\begin{array}{c}\text { Particle density } \\
\rho_{\boldsymbol{s}}\left[\mathbf{k g} \cdot \mathbf{m}^{-\mathbf{3}}\right]\end{array}$ & $\begin{array}{c}\text { Average particle diameter } \\
\boldsymbol{d}_{\boldsymbol{p}}[\mathbf{m m}]\end{array}$ & $\begin{array}{c}\text { Average volumetric particle concentrations in suspension } \\
\boldsymbol{c}_{\boldsymbol{V}}[\%]\end{array}$ \\
\hline Corundum 120 & 3930 & 0.15 & $5,7.5,10$ \\
\hline Corundum 90 & 3940 & 0.21 & $2.5,5$ \\
\hline Corundum 70 & 3940 & 0.29 & $2.5,5$ \\
\hline Corundum 60 & 3970 & 0.34 & 2.5 \\
\hline
\end{tabular}


1st blade

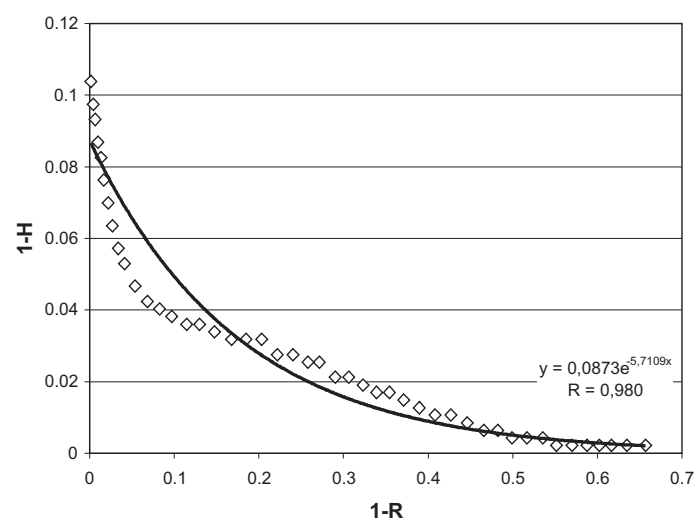

3rd blade

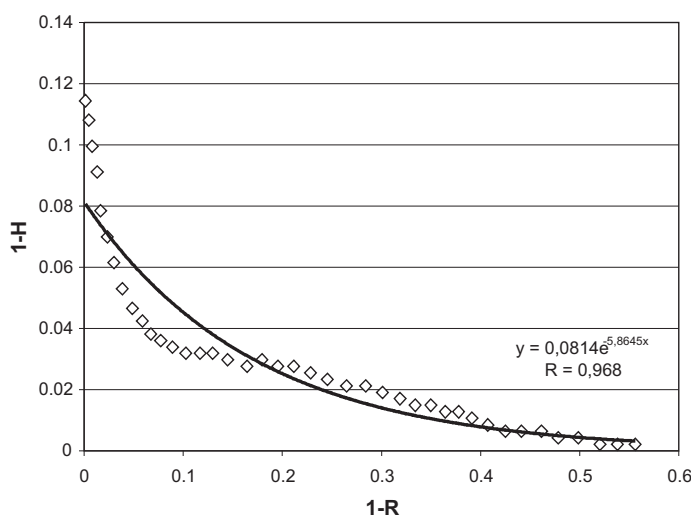

2nd blade

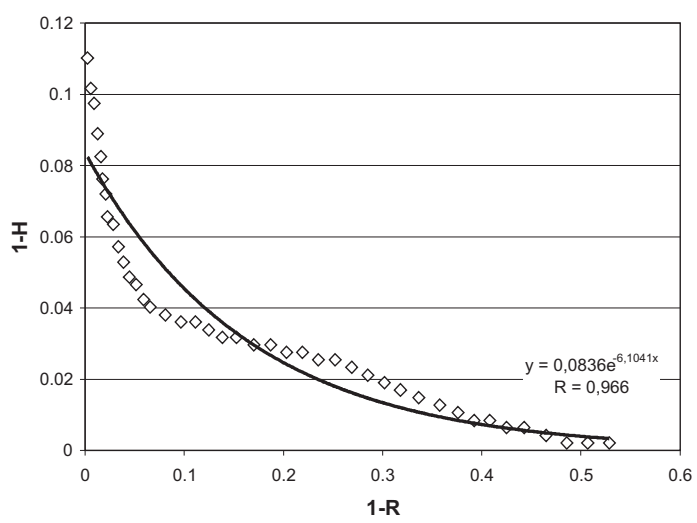

4th blade

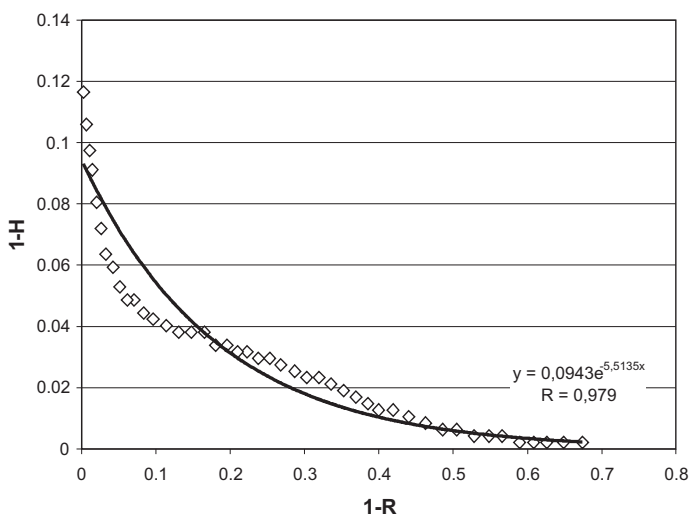

Fig. 4: Example of evaluating of the shape of a worn impeller blade: points - experimental values, curve - calculated regression

mentally found profile of each worn blade at the given time interval $t$ of the erosion process. Each curve was calculated from at least 15 points $(H, R)$ with a regression coefficient better than $R=0.970$ (see example in Fig. 4). The resulting values of parameters $k$ and $C$ were the average values calculated from all individual values of these parameters for each blade. It can be mentioned that the chosen shape of the regression curve $H=f(R)$ fits best to the experimental data among other possible two-parameter equations (e.g. an arbitrary power function or the second power parabola).

After the investigation of the shape of the worn blade, the weight of the blade was measured. All four blades were weighed on a scale with an accuracy $\pm 5 \mathrm{mg}$, and the weight of the blade $m$ related to its initial weight $m_{0}$ (relative weight) was calculated at a given time (period) of the erosion process. The average value of the weight of the blade was calculated as the mean from all measured weights of the four individual blades $m_{o j}$ or $m_{j}$ :

$$
m_{o}(\text { resp. } m)=\frac{\sum_{j=1}^{4} m_{o j}\left(m_{j}\right)}{4} \text {. }
$$

In this way the dependence of quantity $m / m_{0}$ was obtained. At the same time the change in the shape of the particles was observed during the erosion process. Microscopic snap-shots of the corundum particles were made before and after the process, and then their size distributions were compared. No change appeared on their surface (their edges did not become rounded and the corners did not disappear) after the experimental period came to an end (see example in Table 2), and their size distribution was also unchanged.

\section{Results and discussion}

\subsection{Impeller speed vs. erosion rate}

Fig. 5 illustrates the time dependences of the relative weight of a worn impeller $m / m_{0}$ at three selected levels of impeller speed $n$ :

$$
\frac{m}{m_{0}}=1-C_{m, n} t .
$$

Fig. 5 shows the values of parameter $C_{m, n}$ for all levels of impeller speed calculated from the experimental data by the least squares method. The values increase with increasing impeller speed. This dependence can be described in a power form

$$
C_{m, n} \sim n^{2.7}, R=0.998 .
$$


Table 2: Microscopic snap-shots of corundum particles before and after a period of erosion process experiments

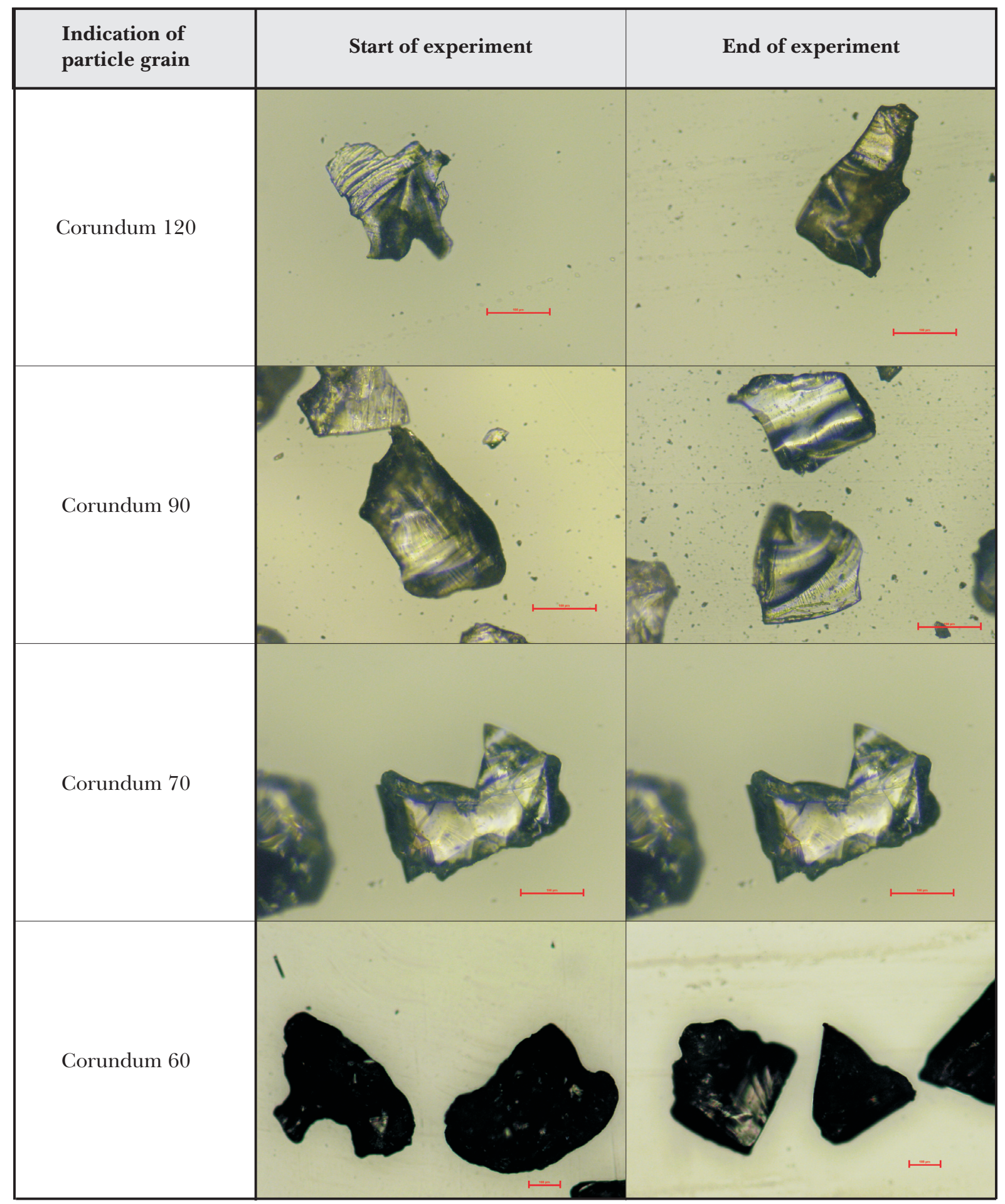

Fig. 6 illustrates the time dependence of the wear rate constant $k$, and Fig. 7 depicts the time dependence of the geometric parameter of the worn blade $C$ at three impeller speed levels. While parameter $k$ oscillates around a certain value throughout the erosion process, parameter $C$ increases with time. Therefore the average value of parameter $k_{a v}$ throughout the period when it is being determined, irrespective of the impeller speed value, can be considered as constant:

$$
-k_{a \vartheta}=3.8 \pm 0.15
$$

The worn blade geometric parameter $C$ increases linearly with the duration of the erosion process $t$

$$
C=C_{n} t .
$$

Fig. 7 shows of the values of parameter $C_{n}$ for all levels of impeller speed, calculated from the experimental data by the least squares method. The values increase with increasing impeller speed. This dependence can be described in a power form

$$
C_{n} \sim n^{2.4}, R=0.939 .
$$




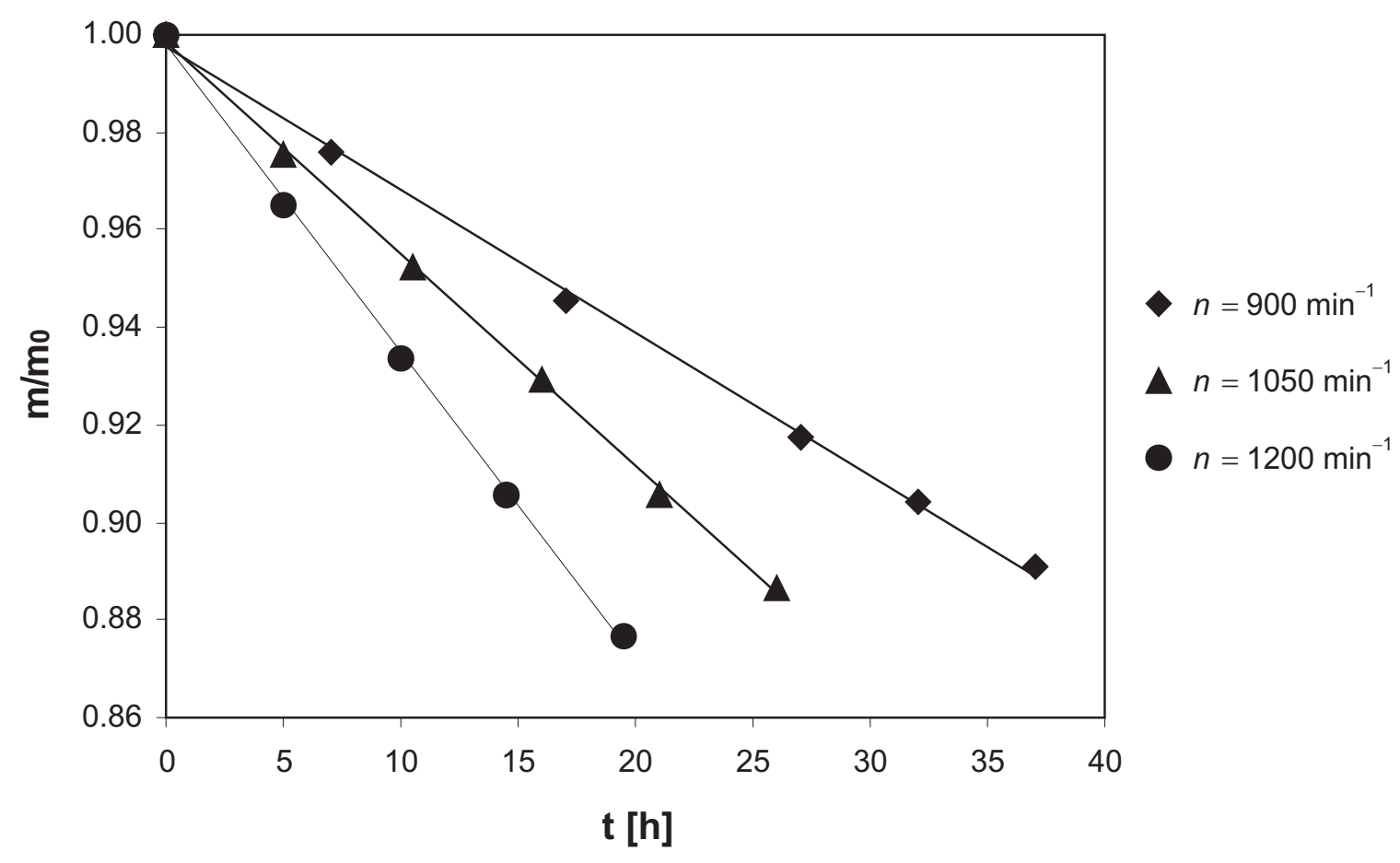

Fig. 5: Time dependence of the relative weight of the impeller blade for different levels of impeller speed: points - experimental values, line - calculated linear regression

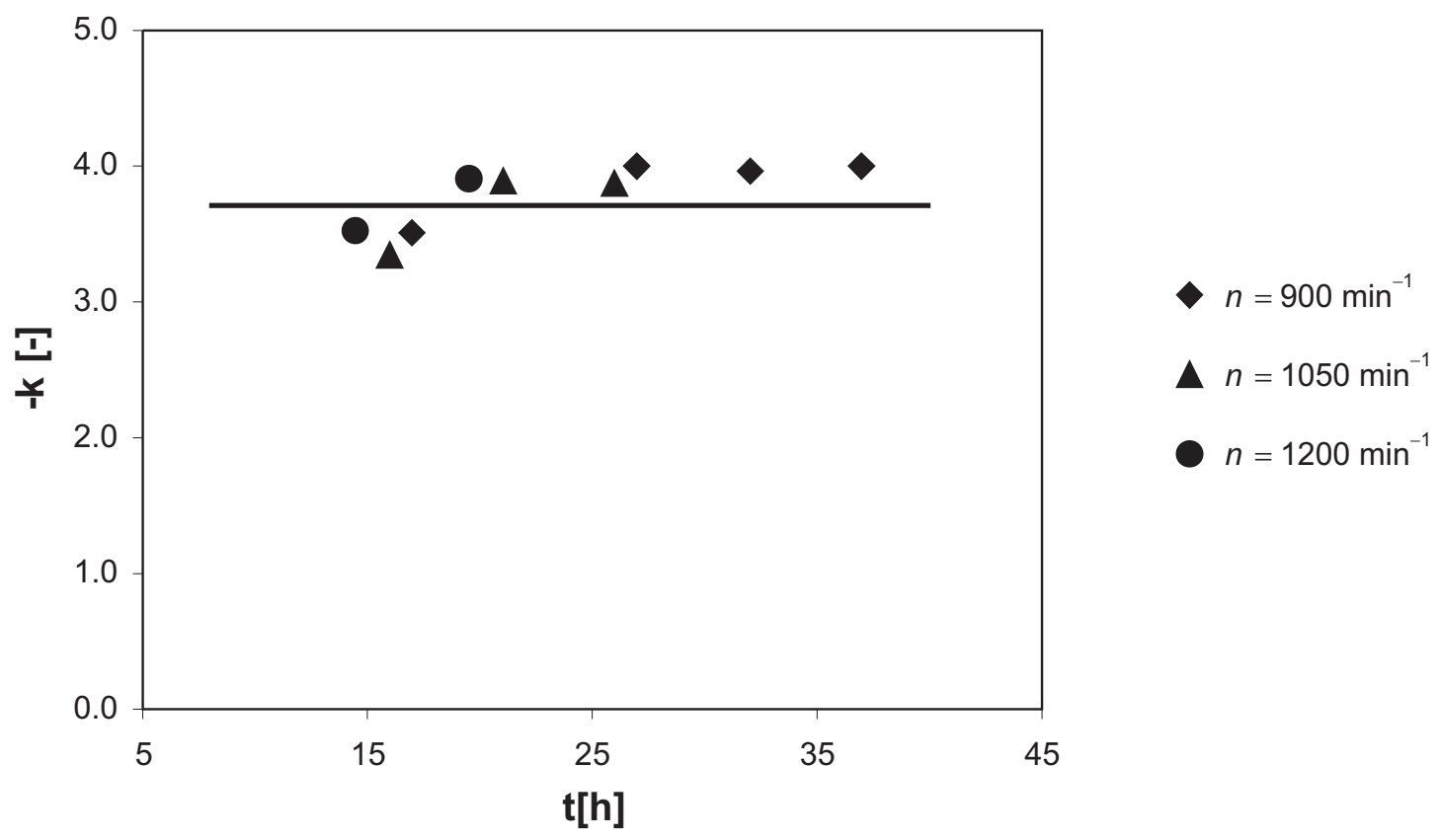

Fig. 6: Time dependence of the wear rate constant for different levels of impeller speed

These results confirm that the wear rate of a pitched blade impeller depends significantly on the impeller speed. This dependence is expressed in the overall relationship $m=m(t)$, while the wear rate constant $k$ does not exhibit any change within the tested impeller speed interval. The power at both dependences $m / m_{0}=f(n)$ and $C_{n}=f(n)$ exceeds two, so it does not depend only on the square of the velocity of the solid particles in a suspension, i.e. not only on their kinetic energy [4]. For metals, the value of the exponent at $n$ can be considered within the interval 2.3-3 [3]. It should only be pointed out that these correlations are valid for the given relative impeller diameter $D / T=1 / 3 \mathrm{D} / \mathrm{T}=1 / 3$, and pitch angle $\alpha=30^{\circ}$.

\subsection{Suspension characteristics vs. erosion rate}

Figs. 8 and 9 illustrate the time dependences of the relative weight of a worn impeller blade $m / m_{0}$ for two investigated levels of average volumetric particle concentration in suspension $c_{V}$ always at three levels of average particle diameter $d_{p}$. These dependences can be expressed for all tested conditions in a linear form 


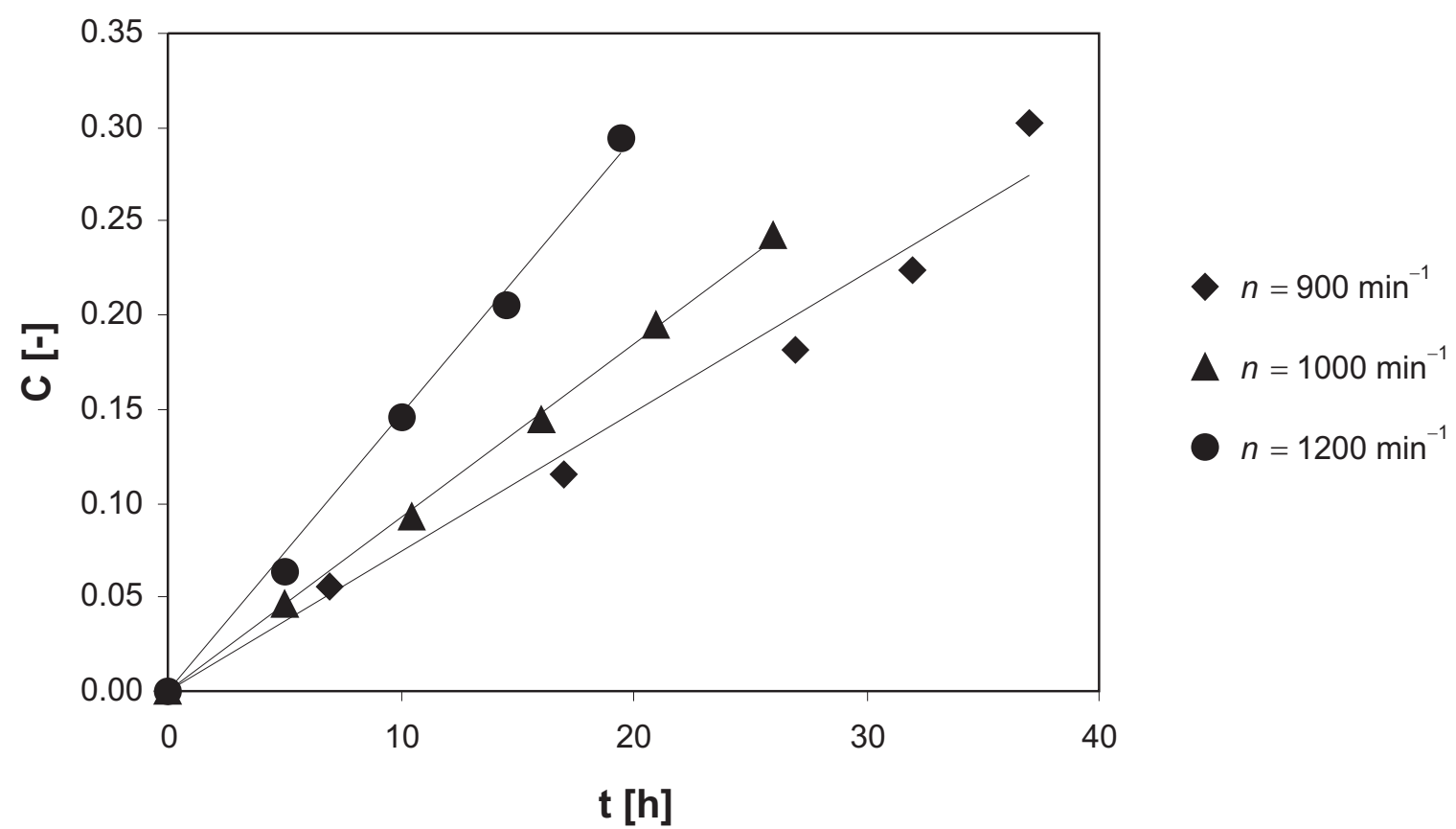

Fig. 7: Time dependence of the geometric parameter of the worn blade for different levels of impeller speed

$$
\frac{m}{m_{0}}=1-C_{m, d} t .
$$

It follows from the two Figures that the value of parameter $C_{m, d}$ increases with increasing value of the average particle diameter. This dependence can be expressed in a power form for both levels of the average volumetric concentric time:

$$
C_{m, d}=0.0347 d_{p}^{2.43}, R=0.999\left(c_{V}=2.5 \%\right),
$$

$$
C_{m, d}=0.0117 d_{p}^{1.717}, R=0.899\left(c_{V}=5 \%\right) .
$$

From Eqs. (11) and (12) we can conclude that the erosion wear rate of a pitched blade impeller exhibits steeper dependence on time at a lower concentration among the concentrations investigated here. A deeper insight into the relation between the rate of erosion wear and the average volumetric particle concentration is provided by Fig. 10, which

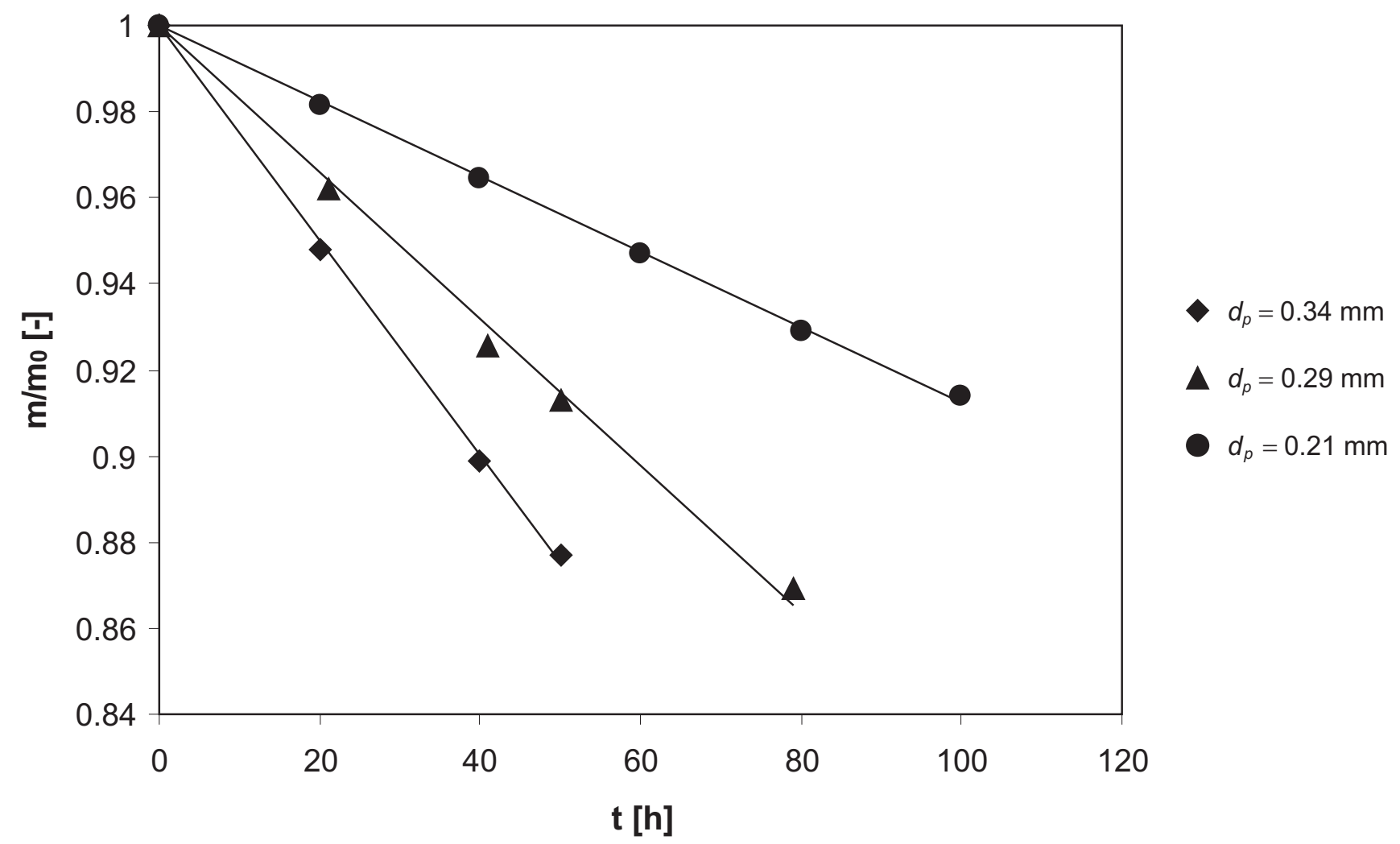

Fig. 8: Time dependence of the relative weight of the impeller blade for different levels of average particle diameter $d_{p}\left(c_{V}=2.5 \%\right)$ : points - experimental values, line - calculated linear regression 


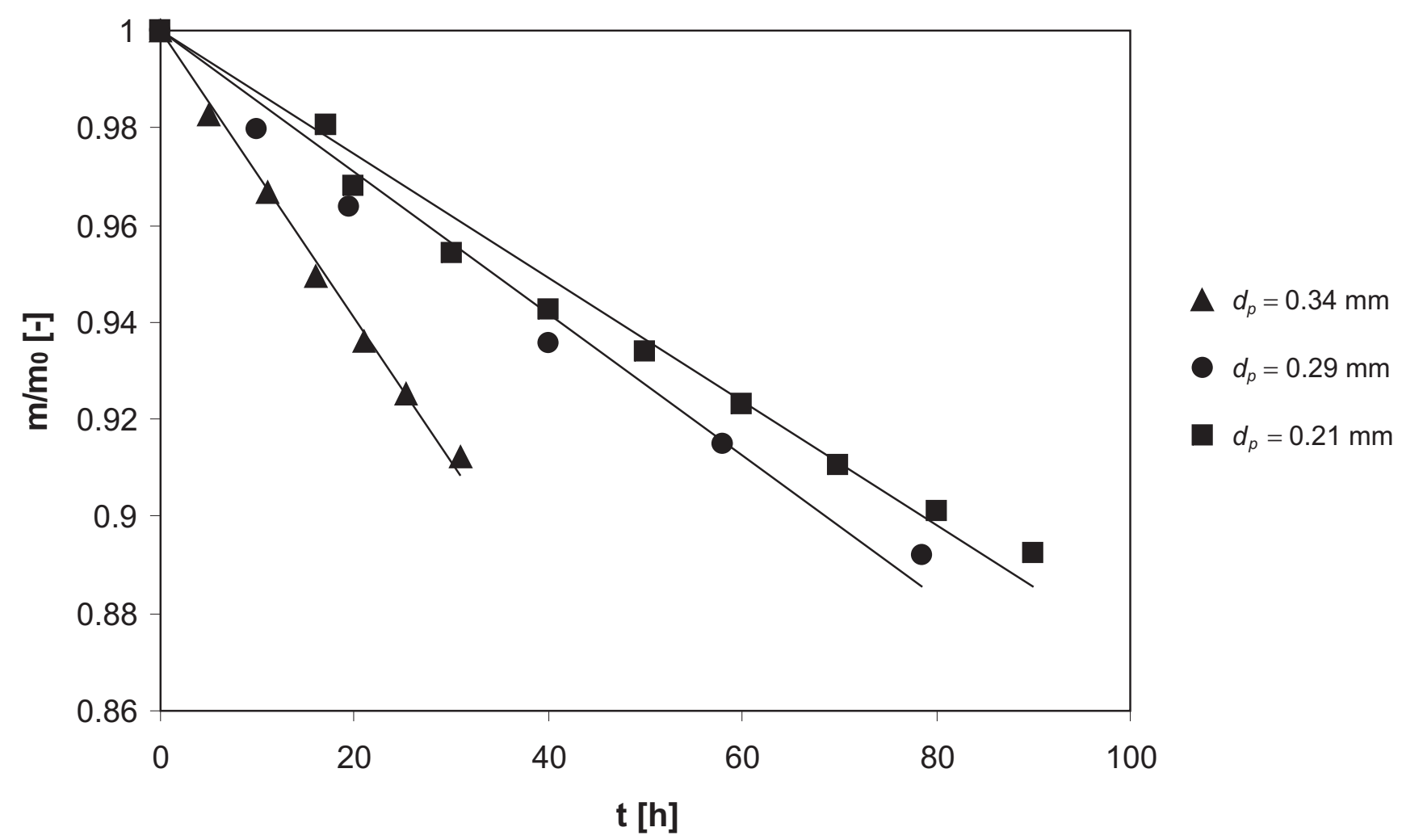

Fig. 9: Time dependence of the relative weight of an impeller blade for different levels of average particle diameter $d_{p}\left(c_{V}=5 \%\right): p o i n t s-$ - experimental values, line - calculated linear regression

shows the time dependence of the relative weight $\mathrm{m} / \mathrm{m}_{0}$ at three levels of volumetric particle concentration $c_{V}$ for the same average particle diameter $d_{p}$. This dependence can be expressed in a linear form

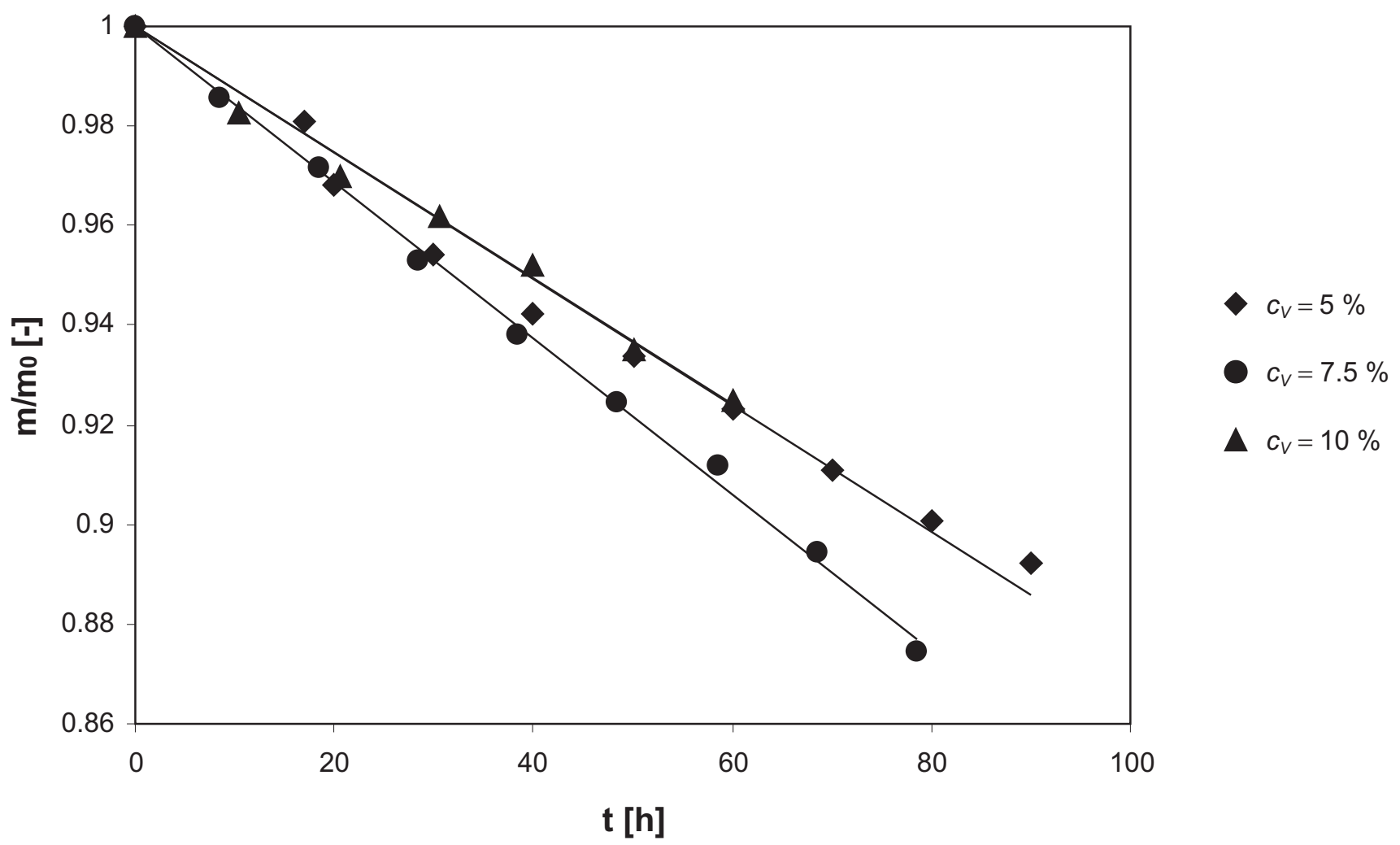

Fig. 10: Time dependence of the relative weight of an impeller blade for different levels of average particle volumetric particle concentration $c_{V}\left(d_{p}=0.15 \mathrm{~mm}\right)$ 


$$
\frac{m}{m_{0}}=1-C_{m, c} t
$$

Table 3: Dependence of parameter $\mathrm{Cm}$,c on the average volumetric particle concentration $\left(d_{p}=0.15 \mathrm{~mm}\right)$

\begin{tabular}{|l|c|c|c|}
\hline $\begin{array}{l}\text { Average volumetric } \\
\text { particle concentration } c_{V}\end{array}$ & 5.0 & 7.5 & 10.0 \\
\hline $\begin{array}{l}\text { Parameter } C_{m, c} \text { in Eq. (13) } \\
{\left[\mathrm{h}^{-1}\right]}\end{array}$ & 0.0013 & 0.0016 & 0.0013 \\
\hline
\end{tabular}

The slope in Eq. (13) $C_{m, c}$ increases up to a certain critical level of the average particle concentration, and then it decreases with increasing $c_{V}$ (see Table 3). This finding is in accordance with the general observation (Suchánek, 2006) that above some critical particle concentration the mutual interaction between striking and reflecting particles reduces their kinetic energy, and their influence on the metal surface of the impeller blade is reduced.

Fig. 11 illustrates the time dependence of the wear rate constant $k$, and Figs. 12, 13 and 14 depict the time dependences of the geometric parameter of the worn blade $C$. While parameter $k$ oscillates around a certain value during the erosion process, parameter $C$ increases with time. Therefore, average values of parameter $k_{a v}$ were calculated for each individual condition $\left(d_{p}\right.$ and $\left.c_{V}\right)$, always over the period in which they were determined (Table 4). It follows from this table that parameter $k_{a v}$ varies in its absolute value within the limits 3.95-4.42. Therefore, we can assume that this parameter is independent of both the size and the concentration of the solid particles in a suspension, with its average value

$$
-k_{s t}=4.10 \pm 0.20 \text {. }
$$

When we compare the values $k_{a v}$ (Eq. 7) and $k_{s t}$ (Eq. 14), we can conclude that they show no significant difference within their variation.

It follows from Figs. 12, 13 and 14 that the geometric parameter of the worn blade increases linearly with the duration of the erosion process $t$

$$
C=C_{t} t \text {. }
$$

Table 4: Mean time values of the wear rate constant $k_{a v}$

\begin{tabular}{|c|c|c|}
\hline $\begin{array}{c}\text { Average particle } \\
\text { diameter } \\
d_{p}[\mathbf{m m}]\end{array}$ & $\begin{array}{c}\text { Average volumetric } \\
\text { particle concentration } \\
c_{V}[\%]\end{array}$ & $k_{a v}[-]$ \\
\hline \multirow{2}{*}{0.15} & 5 & -4.09 \\
\cline { 2 - 3 } & 7.5 & -4.08 \\
\cline { 2 - 3 } & 10 & -4.06 \\
\hline \multirow{2}{*}{0.21} & 2.5 & -4.01 \\
\cline { 2 - 3 } & 5 & -4.14 \\
\hline \multirow{2}{*}{0.29} & 2.5 & -4.42 \\
\hline \multirow{2}{*}{0.34} & 5 & -4.14 \\
\hline & 2.5 & -3.95 \\
\hline
\end{tabular}

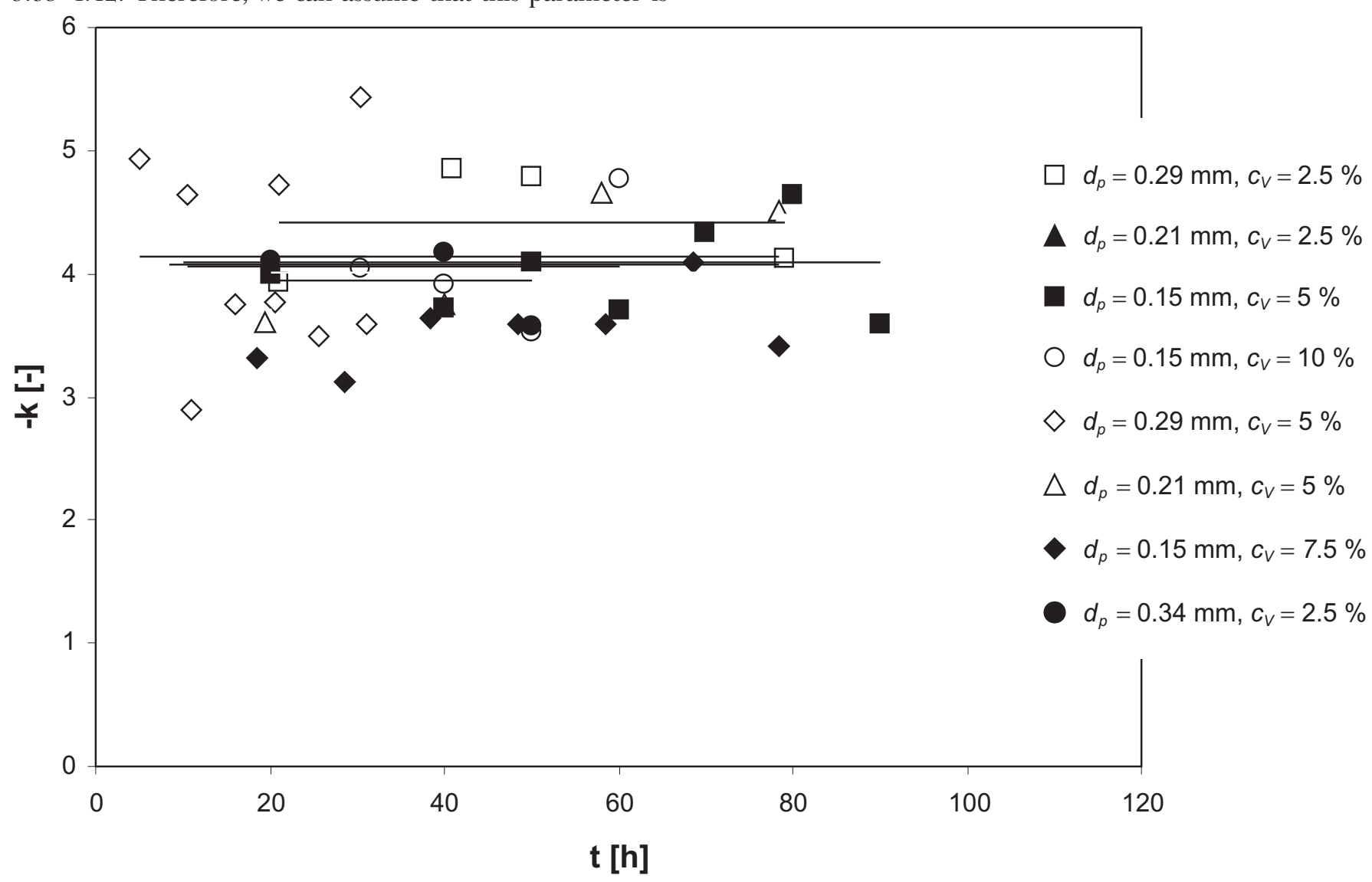

Fig. 11: Time dependence of the wear rate constant for different properties of the suspension 


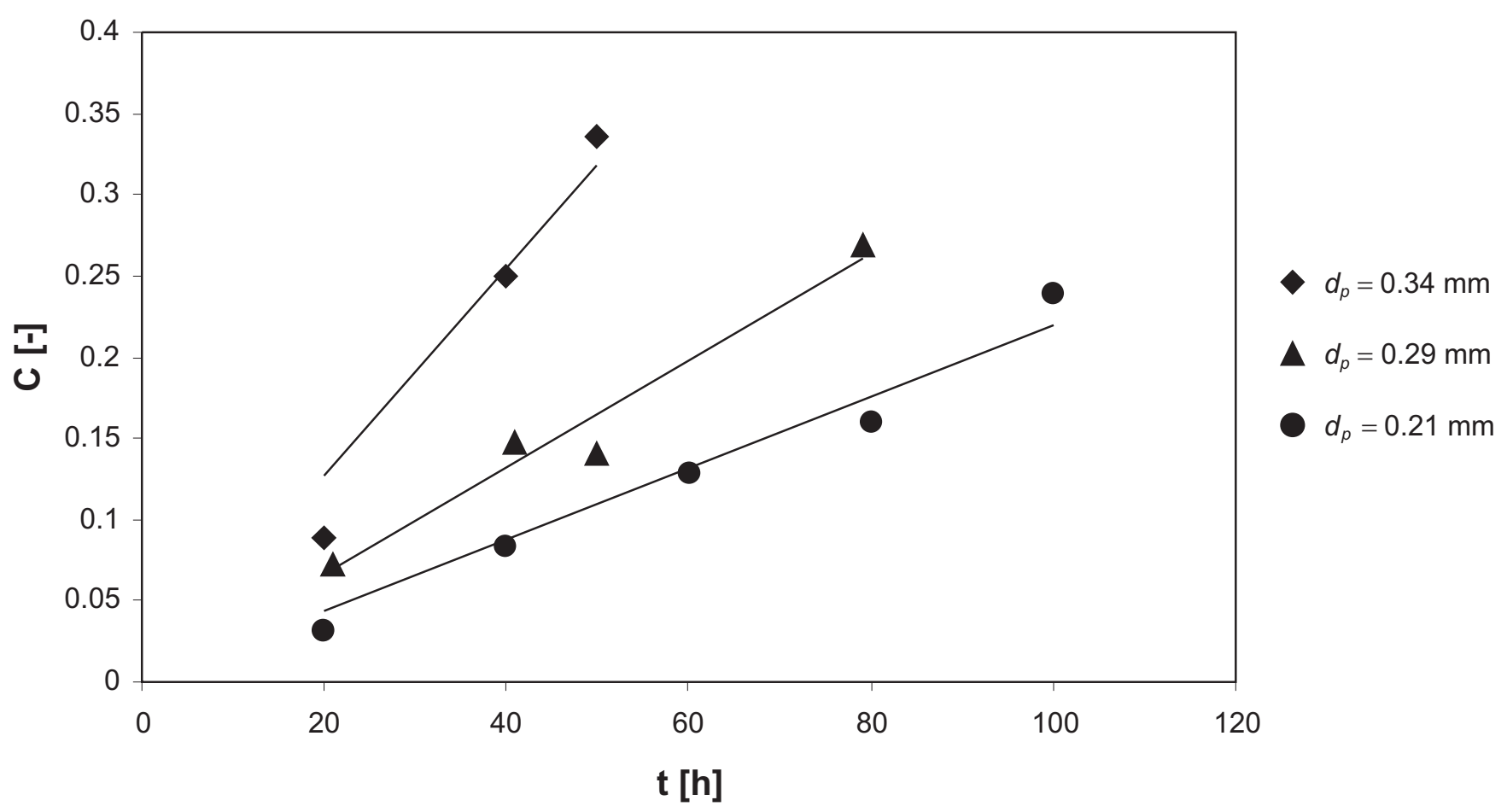

Fig. 12: Time dependence of the geometric parameter of the worn blade for different levels of average particle diameter $d_{p}\left(c_{V}=2.5 \%\right)$

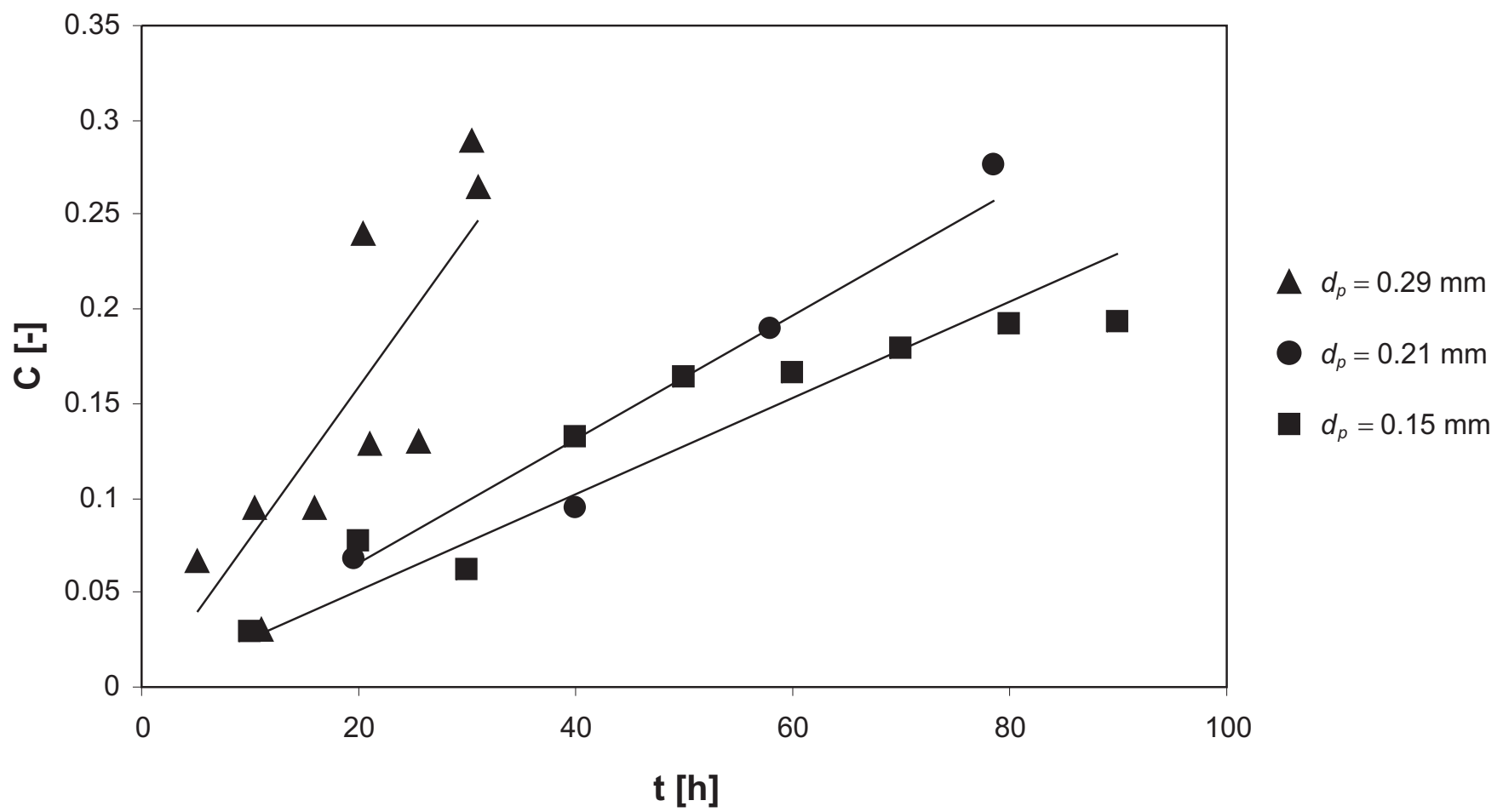

Fig. 13: Time dependence of the geometric parameter of the worn blade for different levels of average particle diameter $d_{p}\left(c_{V}=5 \%\right)$

In accordance with Eqs. (11) and (12), the power relation between parameter $C_{t}$ and the average particle diameter is

$$
C_{t}=0.0717 d_{p}^{2.34}, R=0.952\left(c_{V}=2.5 \%\right)
$$

and

$$
C_{t}=0.0614 d_{p}^{1.76}, R=0.936\left(c_{V}=5 \%\right)
$$

Eqs. (16) and (17) confirm that the erosion wear rate of a pitched blade impeller depends significantly on the diameter of the solid particles in a suspension. Similarly as for the relative weight of the blade (Eq. 13), parameter $C_{t}$ reaches a maximum value within the interval of the average volumetric particle concentrations investigated here (see Table 5). That is, at a higher concentration than $c_{V}=7.5 \%\left(d_{p}=0.15 \mathrm{~mm}\right)$, 


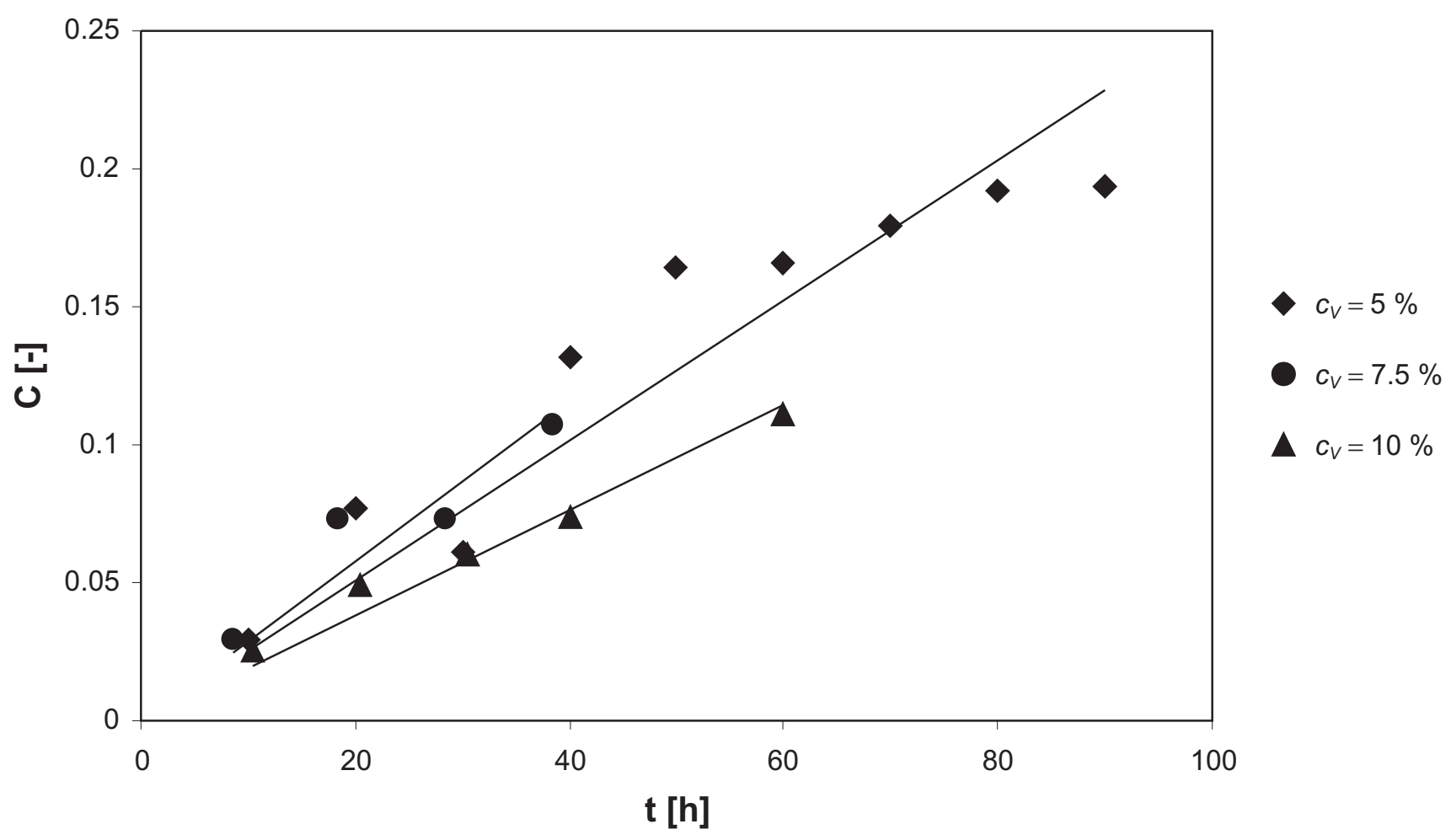

Fig. 14: Time dependence of the geometric parameter of the worn blade for different levels of average volumetric particle concentration $c_{V}\left(d_{p}=0.15 \mathrm{~mm}\right)$

particles of corundum affect each other, with a simultaneous reduction in the interactions between particles and impeller blades.

\section{Conclusions}

A two-parameter equation describing the shape of a worn blade during the erosion process of a pitched blade impeller in a solid-liquid suspension of higher hardness was investigated. It follows from the results of the experiments that the erosion wear rate is proportional to the $2.7^{\text {th }}$ power of the impeller speed and that it exhibits a monotonous dependence (increase) with increasing size of the particles. However, the erosion rate of the pitched blade impeller reaches a maximum at a certain concentration, and above this value it decreases as the proportion of solid particles in the agitated batch increases.

\section{List of symbols}

$b$

baffle width, $m$

C

C

$C_{m}$

$C_{t}$

$c_{V}$

$D$

$D_{0}$

$d_{p}$
$H$
$H$

\section{$h$}

k

m

$n$

R

R

$r$

$s$

$s$
$T$

$T$

$t$

y dimensionless transversal coordinate of the profile of the worn blade

width of impeller blade, $\mathrm{m}$

wear rate constant

weight of impeller blade, $\mathrm{kg}$

impeller speed, $\mathrm{s}^{-1}$

regression coefficient

dimensionless longitudinal (radial) coordinate along the radius of the impeller blade

longitudinal (radial) coordinate along the radius of the impeller blade, $\mathrm{m}$

thickness of the impeller blade, $m$

vessel diameter, $\mathrm{m}$

time, $\mathrm{h}$

transversal coordinate along the width of the blade, $\mathrm{m}$

\section{Greek symbols}

$\alpha \quad$ pitch angle of the blade, deg

$\rho_{l} \quad$ density of liquid, $\mathrm{kg} \cdot \mathrm{m}^{-3}$

$\mu \quad$ dynamic viscosity, $\mathrm{Pa} \cdot \mathrm{s}$

\section{Indices}

$a v$

average value

summation index

related to the concentration of solid particles

related to the diameter of the particles

related to time

initial value 


\section{References}

[1] Fořt, I., Ambros, F., Medek, J.: Study of Wear of Pitched Blade Impellers, Acta Polytechnica, Vol. 40 (2000), No. 5-6, p. 11-14.

[2] Fořt, I., Jirout, T., Cejp, J., Čuprová, D., Rieger, F.: Study of Erosion Wear of Pitched Blade Impeller in a Solid Liquid Suspension, Inzynieria Chemiczna i Proceso$w a$, Vol. 26 (2005), p. 437-450.

[3] Hutchings, I. M.: Wear by Particulates, Chem. Eng. Sci, Vol. 42 (1987), p. 869-878.

[4] Suchánek, J.: Mechanisms of Erosion Wear and Their Meaning for Optimum Choice of a Metal Material in Practical Applications (in Czech), Proceedings of Scientific Lectures of Czech Technical University in Prague (Editor: K. Macek), No. 9, (2006) Prague (Czech Republic), 26 p.

[5] Wu, J., Ngyuen, L., Graham, L., Zhu, Y., Kilpatrick, T., Davis, J.: Minimising Impeller Slurry Wear through Multilayer Paint Modelling, Can. J. Chem. Eng., Vol. 83 (2005), p. 835-842.
[6] Wu, J., Graham, L. J., Noui-Mehidi, N.: Intensification of Mixing, J. Chem. Eng. Japan, Vol. 40 (2007), No. 11, p. 890-895.

Doc. Ing. Tomáš Jirout, Ph.D.

phone: +420 224352681

fax: +420224310292

e-mail: Tomas.Jirout@fs.cvut.cz

Doc. Ing. Ivan Fořt, DrSc.

phone: +420224352713

fax: +420224310292

e-mail: Ivan.Fort@fs.cvut.cz

Department of Process Engineering

Czech Technical University in Prague

Faculty of Mechanical Engineering

Technická 4

16607 Prague 6, Czech Republic 